\title{
KORTE BESCHRIJVING VAN HET LANDSCHAP BILA '.
}

(Met, een kaartje).

Topographie. Het landschap Bila ressorteerende tot de afdeeling Laboean Batoe, residentie Sumatra's Oostkust, wordt begrensd:

Ten Westen: door het landschap Kwaloe, behoorende tot de afdeeling Asahan, en door verschillende nog niet onder geregeld bestuur gebrachte Bataklandschappen gelegen tusschen de afdeelingen Padang Lawas en Toba en Silindoeng der residentie Tapanoeli eenerzijds en het rijk van Bila anderzijds;

Ten Zuiden: door de afdeeling Padang Lawas voornoemd;

Ten Oosten: door de inlandsche rijken van Kota Pinang en Panei, behoorende tot de afdeeling Laboean Batoe, en het Gouvernementsgebied Laboean Batoe;

Ten Noord-Oosten: door de uitwatering der Paneirivier in de straat van Malakka.

De grens tusschen Bila (Sumatra's Oostkust) en Padang Lawas (Sumatra's Westkust) is vastgesteld bij Gouvernements-besluit d.d. 26 Februari 1878 No 9 sub 2; die tusschen Bila en Kwaloe werd geregeld bij besluit van den Resident der Oostkust van Sumatra d.d. 1 November 1888 No 203, terwijl de grenzen tusschen de rijken van Bila, Panei en Kota Pinang bij onderlinge overeenkomst door de vorsten zelf zijn vastgesteld.

Het rijk van Bila omvat het grootendeels in de benedenstreken gelegen eigenlijke landschap Bila; verder de in de bovenstreken gelegen onderhoorige rijkjes van $\mathrm{Si}$ Pare Pare, Merbau, Poelau Djantan (deze drie landschappen zijn gelegen aan de Merbaurivier), en Rantau Prapat, Si Ringo-ringo, Si Bargot, Si Hare-hare, aan de boven Bila-rivier gelegen.

Het grootste gedeelte van het rijk van Bila is vlak, laag en moerassig terrein, en in de benedenstreken staat de grond gedurende den regenmoesson veelal onder water.

1 Van het Departement van Koloniën ter openbaarmaking ontvangen. 


\section{Schetskaart}

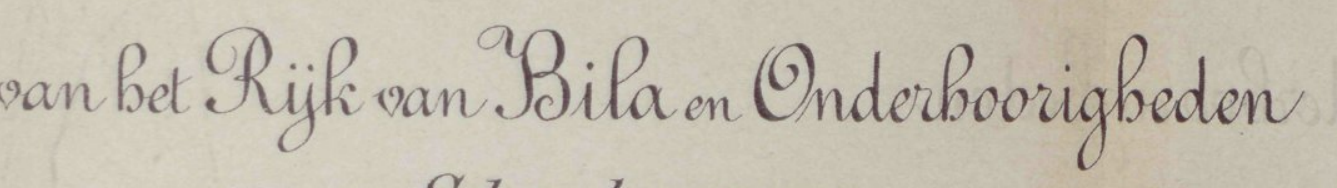

\section{Schaal 1:100.000.}
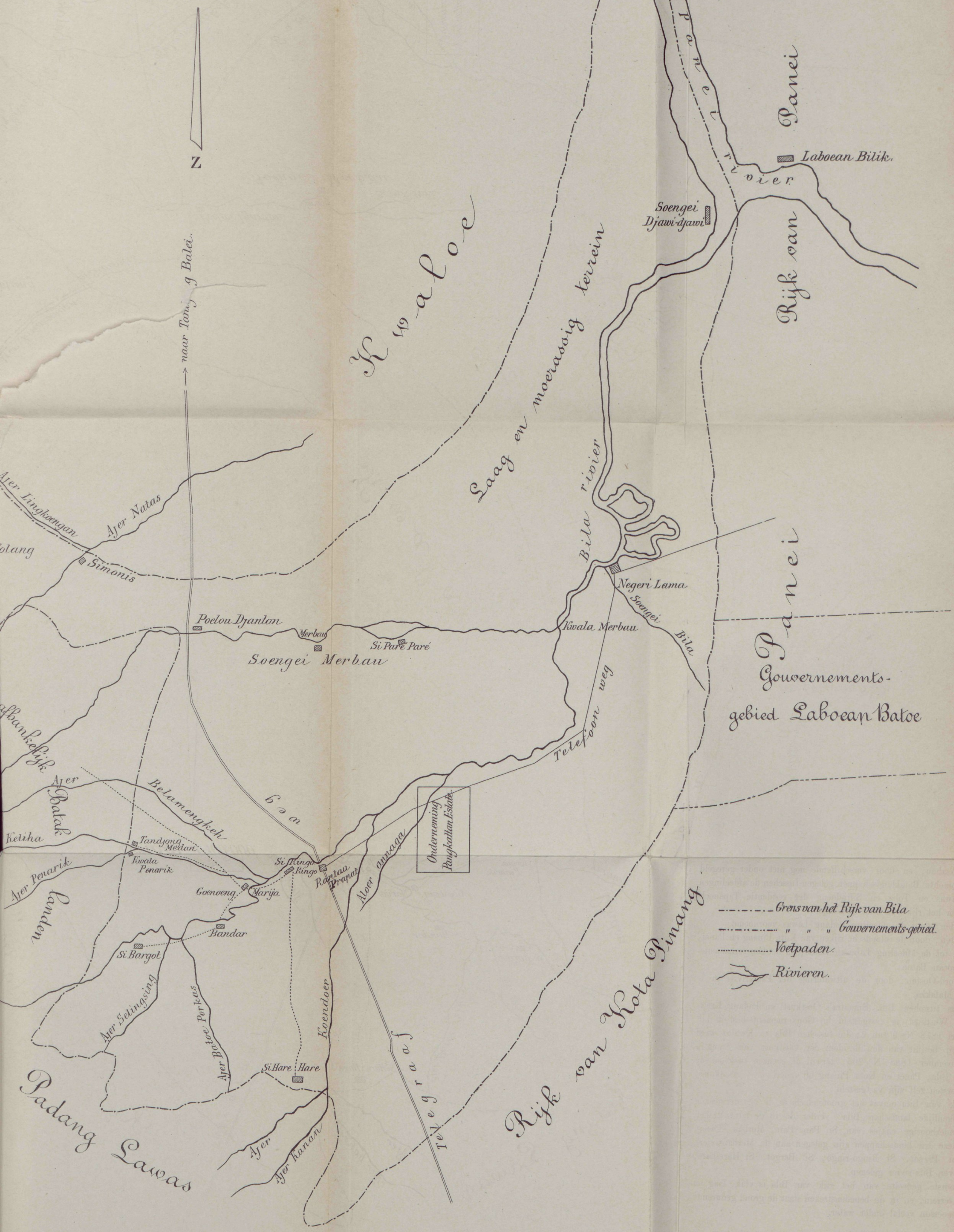
In de bovenstreken, special in het gebied der onderhoorigheden, worlt het terrein henvelachtig en nabij de Bataklanden zelfs zwaar geaccilenteerd.

Het gehede landschap Bila wordt doorsneden door de Bila-rivier, welke ontspringt op den Dolok Narya, an de grens van de Bataklanden en van afe afdeeling Toba en Shindoeng der residentie Tapanoeli.

Even voorbij de kampong Boekit Tinggi vangt zij an door het gebied wan Bila to stroomen, en neemt in haren verderen loop als rechter zijniveren op de Ajer Selingsing, de Ajer Batoe Porkas, de Ajer Koendoer, de Sougei Aloeran Naga en de Ajer Bila en, als linker zijnivieren, de Ajer Katiak, de Ajer Bala Mingke en de Soengei Merban.

Even benedenstrooms van Laboean Bink, standplasts van den controleur der afdeeling Laboean Batoe, stort de Bila-rivier zich in de Panei-rivier.

De Bha-rivier is tot an de Kala Merban voor kleine, geringe diengang hebbende stoombootjes zeer goed bevaarbaar.

Bowen Kwala Merban is de Bila-rivier tot aan de kampong Goenoeng Maria voor vrij groote handelsprauwen bevaarbaar; ook de Soengei Merbau is tot aan de kampong van dien zelfden naam vrij goed bevaarbaar.

In de bovenstreken is de grond vruchtbaarder dan in de benedenstreken. Waarschijnlijk tengevolge der jaarlijksche overstrooming van de benedenstreken, waardoor eene massa vruchtbare slib wordt aangevoerd, gedijt echter de rijstcultuur in de lagere streken veel beter dan in de bovenstreken.

In vroegere jaren was de rijstproductie van Bila zeer beduidend, en werd een groot gedeelte daarvan naar de andere aangrenzende rijken en naar Malakka nitgevoerd.

Sedert de laatste vier jaren is hierin evenwel door voortdurend misgewas eene verandering gekomen.

Van rijstuitvoer is sedert dien geen sprake meer, er wordt juist even voldoende geoogst dat de bevolking daarmede in haar eigen onderhoud kan voorzien.

Naast de rijstcultuur wordt thans in de benedenstreken allerwege op vrij groote schaal de klapper-, pinang- en nipahcultuur gedreven. De inlandsche hoofden en ook de bevolking verkrijgen door deze cultures zulke voldoende inkomsten, dat zij allen bij eenige inspanning in een voor inlanders zeer goeden doen kunnen geraken.

Door voortdurend zijn land middels teroesans (kanalen) te drai- 
neeren, heeft de Vorst van Bìla reeds een belangrijk gedeelte van het midden-gebied van zijn rijk gedeeltelijk of geheel weten droog te leggeu.

In dit gedeelte, speciaal in de omstreken van Negeri Lama, hebben zich een vijftien jaren geleden verschillende tabaksondernemingen gevestigd, die evenwel zooveel last van de jaarlijksche overstroomingen ondervonden, dat zij een voor een te gronde zijn gegaan.

Tusschen Negeri Lama en Rantau Prapat werkt nu nog eene Europeesche onderneming, Pangkatan-Estate, waarop alleen Liberiakoffie en para (getah) geplant wordt.

De inheemsche bevolking der bovenstreken plant naast de padi zeer veel djagong aan, en dit product maakt dan ook een belangrijk deel uit van de voedingsmiddelen dier lieden.

Vruchtentuinen, speciaal van doerian en langsat, worden in geheel Bila veel aangetroffen; manggistantuinen komen in de buurt van Negeri Lama veel voor, en zijn meest in particulier bezit van den Vorst van het landschap.

Het inzamelen van boschproducten als rotan, getah, was, kajoe

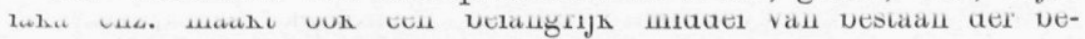
volking uit.

De bosschen zijn rijk aan goede houtsoorten. Door den Vorst van Bila wordt met toestemming van het bestuur aan eenige Chineesche planken- en houtzagers vergunning verleend om die houtsoorten te exploiteeren. Aan delfstoffen is het landschap Bila niet bijzonder rijk. In de bovenstreken, namelijk in de nabijheid van de kampongs Si Ringo-ringo, Bandar en Si Bargot wordt in de Bila-rivier en hare kleine zijrivieren een weinig stofgoud aangetroffen; echter in zulk eene geringe hoeveelheid, dat het wasschen van dat erts zelfs door de inlandsche bevolking als niet loonend wordt beschouwd, en daarom dan ook niet wordt bedreven.

Tusschen de kampongs Bandar en Si Bargot komen belangrijke steenkolenlagen voor. Dit terrein is thans in mijnbouwkundige vergunning uitgegeven aan den heer F. van Peski te Medan; het door dien heer in te stellen nader onderzoek zal moeten aantoonen, of de steenkolen-exploitatie van dat terrein met Europeesch kapitaal mogelijk zal zijn.

Bestuur en rechtspraak. In het rijk van Bila wordt het bestuur uitgeoefend door den Vorst en zijne landsgrooten.

De vorstelijke waardigheid is sedert ruim $1 \frac{1}{2}$ eeuw steeds in het- 
zelfde geslacht gebleven, en van vader op oudsten zoon overgegaan.

In het eigenlijke Bila zijn de landsgrooten de Datoeqs der Soekoe - Radja, der soekoe Rawa, der soekoe Rokan en der soekoe Oeloe die, te zamen met den Tongkoe Djaksa, de Karapatan van Bila vormen.

Behalve bovengenoemde worden de Radja's der onderhoorige landschappen van Si Pare-Pare, Merbau, Poelau Djantan, Rantau Prapat, Si Ringo-Ringo, Si Bargot en Si Hare-Hare eveneens tot de landsgrooten gerekend.

De rechtspraak van den Vorst en rijksgrooten van Bila wordt beheerscht door de door dat inlandsch zelfbestuur, na overleg met den controleur van Laboean Batoe, op den 2den Maart 1900 vastgestelde en op den 5den Mei 1901 door den Resident der Oostkust van Sumatra goedgekeurde en bekrachtigde regeling. De plaats, waar de rechtbank zitting houdt, is Negeri Lama of Soengei DjawiDjawi.

In verband met de uitgestrektheid van het rijk van Bila en de groote last en kosten voor de bevolking van de bovenstreken om hunne zaken en geschillen voor de rechtbank (Karapatan) te Negeri Lama of te Soengei Djawi-Djawi te doen beslechten, werd - mede in verband met de positie der onderhoorige Radja's in de boveustreken, - bepaald dat in de Oeloe Bila en wel te Rantau Prapat mede eens in de drie maanden een rechtbank voor dat doeleinde zoude zitting nemen, waarin de Radja's van de bovenstreken als leden zouden optreden onder presidium van een door den Vorst van Bila, in overeenstemming met het Europeesch Bestuur, aan te wijzen onpartijdig persoon.

Deze regeling werd op 30 Juli 1896 vastgesteld en door den toenmaligen Resident der Oostkust van Sumatra goedgekeurd.

Bevolking. De bevolking, zoomede het regeerend vorstenhuis, is afkomstig van Pagarroejoeng (Sumatra's Westkust). Ruim $l_{\frac{1}{2}}$ eeuw geleden hebben zij zich van Kota Pinang uit naar de Oeloe-Bila begeven, en zich het eerst te Bandar neergezet. Doordat de Vorsten van Bila zich later in de benedenstreken hebben gevestigd, is daar ook successievelijk bevolking gekomen en wel hoofdzakelijk uit Mandheling.

Het taaldialect, dat in het rijk van Bila gesproken wordt, is dan ook hoofdzakelijk de Mandhelingsche taal.

Het rijk van Bila en onderhoorigheden is schaars bevolkt. 
In 't geheel treft men daar aan - volgens door den Vorst verstrekte opgaven - 4676 mannen 4275 vrouwen, 774 jongens en 784 meisjes, derhalve te zamen 10509 menschen.

Klimaat. Het klimaat in Bila is over het algemeen vochtig en warm, doch niet ongezond.

De muskietenplaag is vooral in de benedenstreken zeer groot.

De grootste regenval heeft plaats van October tot einde Januari. In dien tijd staat een groot gedeelte van de benedenstreken onder water.

Tengevolge van de geregeld elk jaar terugkeerende overstroomingen bestaan in de benedenstreken geen wegen of voetpaden. De gemeenschap tusschen de kampongs onderling heeft steeds door middel van sampans te water plaats.

Wegen. Van de telefoonwegen, door het rijk van Bila loopende, wordt intusschen van Negeri Lama uit somtijds gebruik gemaakt, om over de onderneming Pangkatan naar Rantau Prapat te gaan. De bevolking doet dit echter slechts in zeer urgente gevallen, daar ziij liever sver water reist.

Van Rantau Prapat bestaan zeer slecht onderhouden voetpadeu naar Si Bargot, naar Tandjong Medan en Kwala Penarik en naar Si Hare-Hare en Padang Lawas, terwijl mede voetpaden bestaan naar het gebied der om Bila heen gelegen Batakrijkjes.

In de bovenstreken van Bila loopt over Rantau Prapat en Poelau Djantan de telegraaflijn naar Tandjong Balei en Medan; van dezen telegraafweg, eigenlijk ook een voetpad, wordt druk gebruik gemaakt door de bevolking der bovenstreken, zoomede door die van Sumatra's Westkust. Het vervoer van groot vee, speciaal van karbouwen, komende hoofdzakelijk uit Mandheling en Padang Lawas en gaande naar Asahan en Batoe Bahra, is langs bedoelden telegraafweg zeer beduidend.

Dierenrijk. De Bila-rivier en hare zijtakken zijn zeer vischrijk.

Tot in de bovenstreken van Bila wordt de vischvangst dan ook algemeen door de bevolking uitgeoefend en voorziet deze ruimschoots in hare behoefte.

Groot wild als tijgers, rhinocerossen, bij tijden olifanten, komen vooral in de bovenstreken nog veelvuldig voor. In de benedenstreken treft men zeer vele krokodillen aan, waardoor geregeld elk jaar verscheidene personen gedood en verslonden worden. 
De veestapel in het rijk van Bila en onderhoorigheden is zeer gering; paarden worden alleen ten getale van zes door den Vorst van Bila gehouden, het aantal karbouwen, runderen, geiten en schapen is eveneens niet noemenswaardig.

Huizen. Geregelde kampongs, waar vele huizen bijeenstaan, vindt men weinig in Bila.

Deze zijn slechts aanwezig te Soengei Djawi-Djawi, Negeri Lama, Rantau Prapat, Si Ringo-Ringo, Goenoeng Marya, Bandar, Si Bargot, Tandjong Medan, Kwala Pinarik, Si Hare-hare, Poelau Djantan, Merbau, Si Pare-Pare, en in de Oeloe Merbau de kampongs Sielbonis en Tolang.

Het grootste gedeelte der bevolking woont echter zeer verspreid langs de oevers der rivieren. Het toezicht over deze alleen wonende lieden wordt uitgeoefend door zoogenaamde "Ketoea's", dat zijn oudsten of hoofden der ladangs.

Aan elk dezer ketoea's is een bepaald gebied aangewezen waarvoor hij te zorgen heeft, terwijl de ketoea's weder ondergeschikt zijn aan de hoogergenoemde Datoeqs. De huizen staan alle op palen.

Alleen aan de woningen der hoofden wordt eenige zorg besteed. Deze zijn dan voorzien van een planken vloer, planken omwanding en pannen dak. De overige huizen zien er over het algemeen slordig uit. Omwanding en dak wordt met atap-nipah bekleed, terwijl de vloer bestaat nit doorgezaagde niboenglatten; lof- of snijwerk treft men slechts bij uitzondering aan de huizen aan.

Rust en orde worden behoorlijk gehandhaafd terwijl de veiligheid van personen en goederen mede weinig te wenschen laat.

Slavernij en pandelingschap. Slavernij bestaat in het rijk van Bila sinds jaren niet meer, wel het pandelingschap. Het totaal aantal geregistreerde pandelingen bedraagt slechts 35 , en het is te voorzien dat binnen een niet lang tijdsverloop ook deze instelling geheel zal verdwijnen. De voorschriften, waaraan schuldeischers en pandelingen zich te houden hebben, zijn geregeld bij eene door den Vorst en de landsgrooten van Bila na overleg met het Europeesch Bestuur op den 20sten September 1901 vastgestelde en door den Resident der Oostkust van Sumatra op 14. December 1901 goedgekeurde regeling. 
Het voeren van oorlogen, en daarmede gepaard gaande rooven van menschen eu goederen, komt sinds jaren niet meer voor. Door de onderwerping van Bila aan het Nederlandsch-Indisch Gouvernement in 1862 is an dien ouden verderfelijken toestand een einde gemaakt.

Middelen van bestaan. De bevolking van het geheele rijk van Bila is over het algemeen genomen, kalm, rustig, gedwee doch lui. Zij is arm, doch behoefde dit bij een weinig inspanning geenszins te zijn. Zij kent weinig levensbehoeften. Valt nu de rijstoogst bevredigend uit, en wordt er bovendien nog wat verdiend met den verkoop van klapper- en pinang-noten, dan is de bevolking zeer tevreden, en voert zij verder dan ook bijna niets meer uit. Valt de rijstoogst echter tegen, dan wordt in de benedenstreken hard gewerkt aan het maken van atap nipah, terwijl de bevolking der bovenstreken dan genoodzaakt is om boschproducteu te gaan inzamelen.

Het hoofdvoedsel der bevolking is rijst, daarnevens moeten djagong en oebi vermeld worden. De rijstcultuur wordt hoofdzakelijk gedreven op droge velden; in de bovenstreken treft men echter enkele sawahs aan, die geregeld bevloeid kunnen worden. In de benedenstreken wordt de padi dikwijls op moeras-gronden uitgeplant; men zou zich kunnen verbeelden sawahs voor zich te zien, doch op deze gronden is geen sprake van regeling van af- en toevoer van water.

Aan kleeding van mannen en vrouwen valt niets bijzonders waar te nemen.

Zij dragen alleen katoentjes en kains van Europeesch fabrikaat, dat hoofdzakelijk door de Chineesche handelaren van Singapore wordt ingevoerd.

Te Soengei Djawi-Djawi treft men een vrij belangrijke Chineesche kamp aan, waar alles wat de bevolking voor kleeding noodig heeft, verkrijgbaar is.

Met uitzondering van prauwen maken, waariu vooral eenige lieden van Negeri Lama zeer bedreven zijn, houdt de bevolking zich met geen enkelen tak van nijverheid bezig.

Wel worden hier en daar aarden kruiken (gendies) gebakken, en zien deze voorwerpen er niet onaardig uit, doch deze nijverheid kan niet van bijzonder belang worden geacht.

Goud-, zilver- en ijzersmeden treft men onder de inlandsche bevolking niet aan. 
Deze bedrijven worden uitsluitend door Chineezen beoefend.

De wapens, bij de bevolking in gebruik, zijn lans, parang, toembak lada en geweer.

Belastingen enz. Aan den Vorst en landsgrooten van Bila wordt door het Gouvernement een jaarlijksche schadeloosstelling uitbetaald van f 8750 . - voor den afkoop van in vroegeren tijd door het inlandsch zelfbestuur geheven in- en uitvoerrechten.

Met de heffing dezer rechten en accijnzen is voor het landschap Bila thans een Europeesche hoofdopziener der in- en uitvoerrechten belast, met standplaats te Soengei Djawi-Djawi.

Behalve voormelde schadeloosstelling bestaan de inkomsten van den Vorst van Bila nog uit een zeker aandeel der boeten, opgelegd door de Karapatan waarin hij zelf zitting heeft gehouden. Voorts heeft hij het recht, eene belasting te heffen van alle uitgevoerde atap-nipah, welke belasting 0.50 doll. per 1000 stuks atap bedraagt. Voorts heeft hij recht op de zoogenaamde pantjong alas, dat $\frac{1}{10}$ bedraagt van de ingezamelde boschproducten. Dit recht staat de Vorst echter meermalen af aan een of meer zijne familieleden.

Van elken olifant, die in het rijk van Bila geschoten wordt, krijgt de Vorst den rechtertand. In de onderhoorige landschappen komt dit recht niet toe aan den Vorst van Bila, doch aan de daar wonende kleine radja's.

Grondbezit. Het grondbezit is individueel.

Wanneer de bevolking een ladang of een tuin wenscht aan te leggen, kiest zij zelve een aan niemand toebehoorend stuk grond uit, en geeft hiervan slechts kennis aan den ketoea of datoeq. Wanneer daartegen geen overwegende bezwaren bestaan, mag het recht om vrij te beschikken over leegstaanden en niemand toebehoorenden grond nimmer aan de bevolking geweigerd worden.

Heerendiensten. De heerendiensten, welke de bevolking moet verrichten, zijn :

a. wachtdiensten in de kampong;

b. transport van brieven door het Europeesch Bestuur gericht aan den Vorst en landsgrooten of omgekeerd;

$c$. het bouwen van een huis voor den Vorst, en het leveren van de bouwmaterialen daarvoor;

$d$. het bewerken en beplanten van ladangs voor den Vorst en ook voor de andere hoofden; 
e. het vergezellen van den Vorst op zijne reizen, zoowel als roeiers dan wel als gevolg;

$f$. hulp verleenen bij het aanleggen van groote werken in het belang van het rijk, zooals het graven van kanalen.

Het verhuizen naar binnen of buiten het rijk van Bila gelegen kampongs wordt ten allen tijde toegestaan, mits te voren door den belanghebbende al zijne zaken ter plaatse zijner laatste vestiging zijn geregeld en hij al zijne aldaar uitstaande schulden heeft afbetaald.

Godsdienst. De geheele bevolking van het rijk van Bila en onderhoorigheden belijdt den Mohammedaanschen godsdienst. In de benedenstreken worden de godsdienstvoorschriften zeer trouw opgevolgd, in de bovenstreken daarentegen laat dit nog veel te wenschen.

H uwelijksrecht. De gewone wijze van huwelijk is die, waarbij het meisje van haren vader gekocht wordt.

Het hiervoor te betalen bedrag "belandja kawin" geheeten, varieert naar gelang der gegoedheid van de ouders der bruid van 40 tot 80 doll. Bij inlandsche grooten en Vorsten wordt natuurlijk beduidend meer betaald. Het betalen van vermelde belandja is dikwijls een groote hinderpaal voor onvermogende jongelieden om met een meisje van hunne keuze te trouwen.

In zulk een geval wordt het meisje, wauneer zij namelijk daarin toestemt, eenvoudig geschakt. Jongeling en meisje begeven zich dan naar een in de nabijheid wonend hoofd (ketoea) en deelen hem mede, dat zij voornemens zijn met elkaar te huwen. Het meisje blijft dan onder de hoede van zulk een hoofd, dat onverwijld den ouders van jongeling en magd van het gebeurde moet kennis geven. In zulk een geval mogen de ouders der bruid het huwelijk niet beletten. De "belandja" en de door den jongeling te betalen boete worden dan door het betrokken inlandsch hoofd vastgesteld, en de koopsom moet dan later staande het huwelijk bij gedeelten worden betaald.

Wanneer de "belandja" voor het huwelijk in zijn geheel is betaald, wordt de vrouw het eigendom van den man.

Komt de man dan later te sterven, dan is zijn naaste mannelijke erfgenaam verplicht voor weduwe en kinderen te zorgen en kan deze ook met de weduwe huwen (ganti tiker). Wil de vrouw niet tot zulk een huwelijk overgaan, dan is zij verplicht de "belandja", 
die vroeger voor haar betaald werd, aan de erfgenamen terug te geven.

De kinderen blijven steeds het eigendom der erfgenamen.

De weduwe heeft slechts het recht, de kinderen tot hun zevende jaar bij zich te houden; na dien tijd hebben de erfgenamen het recht, de kinderen van hunne moeder af te nemen.

Wauneer echtscheiding door eene vrouw is aangevraagd, wordt zulks wel eens ingewilligd, maar dan alleen met toestemming van den man en tegen terugbetaling van den vollen bruidschat.

Eene schetskaart van het rijk van Bila wordt hierbij gevoegd. 